\title{
Noninvasive ventilation during the weaning process in chronically critically ill patients
}

\author{
Jesus Sancho ${ }^{1,2}$, Emilio Servera ${ }^{1,2,3}$, Luis Jara-Palomares $\mathbb{1}^{4}$, Emilia Barrot ${ }^{4}$, \\ Raquel Sanchez-Oro-Gómez ${ }^{4}$, F. Javier Gómez de Terreros ${ }^{5,6}$, \\ M. Jesús Martín-Vicente ${ }^{5,6}$, Isabel Utrabo ${ }^{5,6}$, M. Belen Núñez ${ }^{6,7}$, \\ Alicia Binimelis ${ }^{6,7}$, Ernest Sala ${ }^{6,7}$, Enrique Zamora ${ }^{8}$, Gonzalo Segrelles ${ }^{8}$, \\ Angel Ortega-Gonzalez ${ }^{9}$ and Fernando Masa ${ }^{5,6}$ on behalf of the Spanish \\ Respiratory Intermediate Care Units Group
}

Affiliations: ${ }^{1}$ Respiratory Care Unit, Respiratory Medicine Dept, Hospital Clínico Universitario, Valencia, Spain. ${ }^{2}$ INCLIVA Institute of Health Research, Valencia, Spain. ${ }^{3}$ Dept of Physical Therapy, Universitat de Valencia, Valencia, Spain. ${ }^{4}$ Unidad Médico-Quirurgica de Enfermedades Respiratorias, Hospital Virgen del Rocio, Seville, Spain. ${ }^{5}$ Servicio de Neumología, Hospital San Pedro Alcántara, Cáceres, Spain. ${ }^{6}$ Centro de Investigación Biomédica de Enfermedades Respiratorias (CIBERES), University Carlos III, Madrid, Spain. ${ }^{7}$ Servicio de Neumología, Hospital Son Espases, Palma de Mallorca, Spain. ${ }^{8}$ Intermediate Care Unit, Pulmonology Dept, La Princesa Institute for Health Research, Hospital Universitario de La Princesa, Madrid, Spain. ${ }^{9}$ Servicio de Neumología, Hospital Nuestra Señora del Prado, Talavera de la Reina, Spain.

Correspondence: Jesus Sancho, Respiratory Care Unit, Respiratory Medicine Dept, Hospital Clínico Universitario, Blasco Ibañez 17, 46010 Valencia, Spain. E-mail: jesus.sanchođuv.es

ABSTRACT Chronically critically ill patients often undergo prolonged mechanical ventilation. The role of noninvasive ventilation (NIV) during weaning of these patients remains unclear. The aim of this study was to determine the value of NIV and whether a parameter can predict the need for NIV in chronically critically ill patients during the weaning process.

We conducted a prospective study that included chronically critically ill patients admitted to Spanish respiratory care units. The weaning method used consisted of progressive periods of spontaneous breathing trials. Patients were transferred to NIV when it proved impossible to increase the duration of spontaneous breathing trials beyond $18 \mathrm{~h}$.

231 chronically critically ill patients were included in the study. 198 (85.71\%) patients achieved weaning success (mean weaning time $25.45 \pm 16.71$ days), of whom 40 (21.4\%) needed NIV during the weaning process. The variable which predicted the need for NIV was arterial carbon dioxide tension at respiratory care unit admission (OR 1.08 (95\% CI 1.01-1.15), $\mathrm{p}=0.013$ ), with a cut-off point of $45.5 \mathrm{mmHg}$ (sensitivity 0.76 , specificity 0.67 , positive predictive value 0.76 , negative predictive value 0.97 ).

NIV is a useful tool during weaning in chronically critically ill patients. Hypercapnia despite mechanical ventilation at respiratory care unit admission is the main predictor of the need for NIV during weaning.

@ERSpublications

NIV is a useful tool during weaning in chronic critically ill patients independent of their premorbid condition http://ow.ly/j4Av304sEoJ

This article has supplementary material available from openres.ersjournals.com

Received: May 272016 | Accepted after revision: Sept 102016

Conflict of interest: None declared.

The content of this work is @ the authors or their employers. Design and branding are @ERS 2016. This article is open access and distributed under the terms of the Creative Commons Attribution Non-Commercial Licence 4.0. 


\section{Introduction}

Progress in the treatment of acute critical episodes has resulted in higher survival rates for patients admitted to intensive care units (ICU). However, these advances have also given rise to the appearance of a growing population characterised by prolonged dependence on mechanical ventilation (MV), requiring a tracheostomy and other life sustaining therapies [1]. These patients, known as chronically critically ill patients, represent up to $14 \%$ of patients admitted to ICUs for invasive MV, have an increased risk of in-hospital morbidity and mortality, and account for $>37 \%$ of ICU costs [2]. For these reasons they are often transferred to specialised weaning units with multidisciplinary teams, which can offer advanced weaning protocols, a more comfortable environment for the patients and their families, and lower healthcare costs in comparison with ICUs $[3,4]$.

The two most common weaning methods used with patients with prolonged MV are pressure support ventilation and spontaneous breathing trials (SBT) [3]. Recently, JUBRAN et al. [5] have found that the use of SBT with a tracheostomy collar results in a shorter median weaning time, but with no effect on survival at 6 and 12 months. Noninvasive ventilation (NIV) has demonstrated its utility in shortening the MV weaning time in stable patients recovering from an episode of acute respiratory failure who had previously failed a conventional weaning trial [6]. It has been found to be able to reduce rates of death and pneumonia without increasing the risk of weaning failure, mainly in patients with chronic obstructive pulmonary disease (COPD) [6,7]. The use of NIV for patients with prolonged MV has also been considered, but the number of studies addressing this question is limited and mainly focus on patients with COPD [8-10].

The aim of this study was to determine the role of NIV during weaning in chronically critically ill patients with prolonged MV and whether a clinical or functional parameter can predict the need for NIV in chronically critically ill patients during the weaning process.

\section{Materials and methods}

This is a multicentre prospective study that was conducted in the respiratory care units affiliated to the Spanish Respiratory Society. It included those chronically critically ill patients with prolonged MV admitted to these respiratory care units from ICUs between December 2013 and December 2014. A chronically critically ill patient was defined as one who has survived an acute critical illness or injury but had not yet recovered to the point of liberation from life sustaining therapies [1]. Prolonged MV was defined, in accordance with the National Association for Medical Direction on Respiratory Care recommendations, as those patients who need $\mathrm{MV}$ for $>6 \mathrm{~h} \cdot \mathrm{day}^{-1}$ for $>21$ consecutive days [11]. Informed consent was obtained from every patient and the protocol was approved by the ethics committees of the different hospitals. Exclusion criteria were refusal to participate in the study and irreversible neuromuscular disease in patients who develop ventilatory failure as a consequence of the neuromuscular process and who were candidates for long-term MV at home [1].

\section{Data collection}

The following information was collected from each chronically critically ill patient admitted to the respiratory care units: age, sex, premorbid medical conditions and premorbid medical status as measured by the Charlson comorbidity index [12], medical diagnosis which precipitated the critical event, duration of ICU stay, and duration of MV in the ICU. At the time of admission to the respiratory care unit, data regarding blood chemistry, blood gas, the presence of critical illness polyneuropathy/myopathy and the Acute Physiology and Chronic Health Evaluation (APACHE) II [13] were recorded.

\section{Weaning protocol}

At respiratory care unit admission, the tracheostomy tube was changed to one which was cuffed, fenestrated and had an inner cannula, and MV was established in pressure support ventilation. The level of positive end expiratory pressure was $4-6 \mathrm{cmH}_{2} \mathrm{O}$ and pressure support was set in order to achieve a tidal volume of $8 \mathrm{~mL} \cdot \mathrm{kg}^{-1}$ of predicted body weight. The back-up rate was set at $12-18$ breaths $\cdot \mathrm{min}^{-1}$ and trigger sensitivity was set at $-1 \mathrm{cmH}_{2} \mathrm{O}$. The ventilator settings were then readjusted for patient comfort and taking arterial blood gas values into account, in order to attempt to maintain arterial carbon dioxide tension $\left(\mathrm{PaCO}_{2}\right)<45 \mathrm{mmHg}$. Inspiratory oxygen fraction $\left(\mathrm{FIO}_{2}\right)$ was adjusted in order to maintain arterial oxygen saturation measured by pulse oximetry $\left(\mathrm{SpO}_{2}\right)>90 \%$. Bronchoscopy was performed in order to check the upper and lower airways for possible lesions related to intubation or tracheostomy tubes.

Over the following days, SBT was performed. During the SBT, the cuff of the tracheostomy tube was deflated and a fenestrated inner cannula was used. A heat and moisture exchanger with oxygen was placed at the top of the tracheostomy tube in order to maintain $\mathrm{SpO}_{2}>92 \%$. The frequency and duration of SBT was increased progressively over the following days according to patient tolerance. SBT was interrupted 
and MV was initiated and maintained for the remainder of the 24-h period if the patient presented with at least one of following: agitation; diaphoresis; depressed mental status; cyanosis; dyspnoea; accessory muscle activity; $\mathrm{SpO}_{2}<90 \%$; respiratory rate $>35$ breaths $\cdot \mathrm{min}^{-1}$ or increased by $50 \%$; heart rate $>140$ beats. $\mathrm{min}^{-1}$ or increased by $20 \%$; systolic blood pressure $>180 \mathrm{mmHg}$ or increased by $20 \%$; systolic blood pressure $<90 \mathrm{mmHg}$; or cardiac arrhythmia. Once the patient was able to maintain spontaneous ventilation for $24 \mathrm{~h}$ the tracheostomy tube was replaced by one which was uncuffed and fenestrated, and a cap was placed at the top of the tracheostomy tube. When the patient was able to maintain adequate ventilation with the capped tracheostomy tube and was able to expel respiratory secretions by coughing, the tracheostomy tube was removed and the tracheostomy closed.

Those patients whose weaning process could not be completed due to the need for MV during the night were transferred to NIV. The criterion for transfer to NIV was when it proved impossible to increase the duration of SBT beyond $18 \mathrm{~h}$ during five consecutive days [5]. Two different techniques were used to affect the transfer to NIV. In some respiratory care units, the tracheostomy was replaced by a tracheal button and NIV was initiated; in others, NIV was applied with the tracheostomy tube having been capped, its cuff deflated and using a fenestrated inner cannula. In both cases, NIV was applied through a nasal or oronasal mask in pressure support mode and with oxygen added if necessary. The ventilator was initially set up so as to attain a tidal volume of $\sim 8-10 \mathrm{~mL} \cdot \mathrm{Kg}^{-1}$. The back-up respiratory rate was set at $12-16$ breaths $\cdot \mathrm{min}^{-1}$ and the inspiratory trigger sensitivity at $-1 \mathrm{cmH}_{2} \mathrm{O}$. The ventilatory parameters were then readjusted in order to achieve effective ventilation $\left(\mathrm{PaCO}_{2}<45 \mathrm{mmHg}\right.$ and time spent with $\mathrm{SpO}_{2}<90 \%$ at night using NIV $<5 \%)$. Once NIV was tolerated by the patient and effective ventilation had been achieved the tracheal button or tracheostomy tube was removed and the tracheostomy was closed.

\section{Patient management}

During the stay in the respiratory care unit all patients were continuously monitored via pulse oximetry and electrocardiography. Possible factors that could interfere with the weaning process were identified and treated. Patients received physical therapy for critical illness polyneuropathy/myopathy and any complications arising during the respiratory care unit stay were treated. Respiratory secretions were managed with tracheal suctioning with a conventional catheter via the tracheostomy tube three times a day or when necessary (dyspnoea, sense of retained secretions, decreased $\mathrm{S}_{\mathrm{PO}_{2}}$ or decreased tidal volume during MV).

\section{Outcomes}

Weaning was considered to have been a success when complete liberation from MV occurred or only nocturnal NIV was required for seven consecutive days [11]. Time to weaning success, length of stay at the RCU, in-hospital survival and destination after respiratory care unit discharge were recorded, as well as 1-year survival.

\section{Statistical analysis}

Data were expressed as mean \pm SD for continuous normally distributed variables, median (interquartile range) for not normal distributed variables and as frequency counts and percentages for binary and categorical variables. Data comparisons were performed using Student's t-test and the Mann-Whitney test for normally and not normally distributed data, respectively; categorical data were compared using the Chi-squares test. Forward stepwise logistic regression analysis was performed to determine those variables which were independently associated with the need for NIV in order to achieve weaning success. Variables were first examined using univariate analysis; those variables that exhibited a significant association in the previous univariate analysis $(\mathrm{p}<0.2)$ were included in the multivariable model. Receiver operating characteristic curves were used to identify a cut-off point for those variables that best predicted the patients for whom NIV was able to play a role during the weaning process. Statistical significance was taken as $\mathrm{p}<0.05$.

\section{Results}

During the period of the study 4609 patients were admitted to different respiratory care units, of whom 231 patients were chronically critically ill, were referred due to prolonged MV and were then enrolled. Table 1 shows the main demographic and clinical data for patients at respiratory care unit admission. The main premorbid medical conditions were hypertension (48.9\%), diabetes mellitus (22.5\%), congestive heart failure (19\%) and COPD (18.6\%). 84 (36.4\%) patients were current smokers. The main acute illnesses resulting in chronic critical illness were community acquired pneumonia $(n=30(13 \%))$, cardiac valve replacement surgery $(n=19(8.2 \%))$, thoracic surgery $(n=12(5.2 \%))$ and neurosurgery $(n=11(4.8 \%))$.

The mean respiratory care unit stay was $56.99 \pm 40.52$ days. 29 (12.6\%) patients died during their stay at the respiratory care unit. $198(85.71 \%)$ patients achieved weaning success and the mean weaning time was 
$25.45 \pm 16.71$ days. At respiratory care unit discharge, patients presented with $\mathrm{pH} 7.42 \pm 0.03$, arterial oxygen tension $80.31 \pm 17.02 \mathrm{mmHg}, \mathrm{PaCO}_{2} 41.01 \pm 5.35 \mathrm{mmHg}$ and $\mathrm{FIO}_{2} 0.21 \pm 0.01$. Four (1.7\%) patients were discharged at home with long-term MV via a tracheostomy tube due to it proving impossible to achieve weaning success. In one patient, after successful removal of MV, the tracheostomy could not be closed due to the lack of an effective cough for the removal of respiratory secretions. At the end of the respiratory care unit stay $149(64.5 \%)$ patients were discharged to their homes, 17 (7.4\%) patients were transferred to other hospital departments (mainly thoracic surgery and respiratory medicine departments), and 36 (15.6\%) patients were transferred to long-term facilities in order to continue with specific physical therapy for their critical illness polyneuropathy/myopathy. After respiratory care unit discharge $32 \%$ of the patients died during the first year.

Among patients who achieved weaning success, 40 (21.4\%) patients needed NIV during the weaning process. Statistical differences were found between patients who needed NIV and those who did not in APACHE II, the critical illness triggering the chronic critical illness and $\mathrm{PaCO}_{2}$ at respiratory care unit admission (tables 1 and 2). Regarding premorbid medical conditions, differences were found between the NIV group and those who did not require NIV in the proportions of patients with obstructive sleep apnoea syndrome $(12.8 \%$ versus $3.4 \%, \mathrm{p}=0.02)$, congestive heart failure $(30.8 \%$ versus $12.3 \%, \mathrm{p}=0.006)$ and chronic renal failure $(17.5 \%$ versus $4.1 \%, \mathrm{p}=0.003)$. In the NIV group there were higher proportions of patients with home continuous positive airway pressure $(10.3 \%$ versus $2.7 \%, \mathrm{p}=0.038)$ and home NIV ( $7.7 \%$ versus $0.7 \%, \mathrm{p}=0.007$ ). No statistical differences were found between the NIV and non-NIV groups with regard to the proportion of patients with critical illness polyneuropathy/myopathy $(72.7 \%$ versus $74.6 \%, \mathrm{p}=0.863$ ). At respiratory care unit discharge, all those patients in whom NIV had been employed during the weaning protocol were using long-term NIV (supplementary material).

The results of the univariate logistic regression analysis, carried out to establish which variables most accurately predicted the need for NIV during weaning, are shown in table 3 . In the multivariate analysis, the only variable which predicted the need for NIV was $\mathrm{PaCO}_{2}$ at respiratory care unit admission (OR 1.08 (95\% CI 1.01-1.15), $\mathrm{p}=0.013)$. In the receiver operating characteristic curve analysis, the variable with the highest area under the curve was $\mathrm{PaCO}_{2}$ at respiratory care unit admission (area under the curve 0.694 (95\% CI 0.560-0.828), $\mathrm{p}=0.008$ ). A cut-off point of $45.5 \mathrm{mmHg}$ for $\mathrm{PaCO}_{2}$ was the best predictor for the identification of the patients in whom NIV would become necessary during the weaning process (sensitivity 0.76 , specificity 0.67 , positive predictive value 0.76 , negative predictive value 0.97 ).

TABLE 1 Demographic and clinical data of the 231 chronically critically ill patients at admission to the respiratory care unit

\begin{tabular}{|c|c|}
\hline & Patients \\
\hline Male/female & $149 / 82$ \\
\hline Age years & $62.76 \pm 15.03$ \\
\hline Medical/surgical cause of critical illness & $130 / 101$ \\
\hline Charlson index & $1.73 \pm 1.74$ \\
\hline APACHE II & $12.49 \pm 5.34$ \\
\hline Intensive care stay days & $44.72 \pm 23.05$ \\
\hline Mechanical ventilation in intensive care days & $36.74 \pm 23.93$ \\
\hline pH & $7.35 \pm 0.14$ \\
\hline $\mathrm{PaO}_{2} \mathrm{mmHg}$ & $97.09 \pm 49.78$ \\
\hline $\mathrm{PaCO}_{2} \mathrm{mmHg}$ & $46.65 \pm 9.44$ \\
\hline $\mathrm{FlO}_{2}$ & $0.43 \pm 0.16$ \\
\hline Leukocytes per L & $10152.78 \pm 3612.81$ \\
\hline Neutrophils \% & $75.42 \pm 11.57$ \\
\hline Haemoglobin $\mathrm{g} \cdot \mathrm{dL}^{-1}$ & $9.66 \pm 1.49$ \\
\hline Haematocrit \% & $29.21 \pm 4.57$ \\
\hline Platelets per $\mathrm{L}$ & $291278.35 \pm 0.01$ \\
\hline Sodium mmol. $\mathrm{L}^{-1}$ & $138.73 \pm 5.50$ \\
\hline Potassium mmol- $\mathrm{L}^{-1}$ & $4.03 \pm 0.52$ \\
\hline Blood urea nitrogen $\mathrm{mg} \cdot \mathrm{dL}^{-1}$ & $52.46 \pm 38.98$ \\
\hline Creatinine $\mathrm{mg} \cdot \mathrm{dL}^{-1}$ & $0.76 \pm 0.56$ \\
\hline Serum albumin $\mathbf{g} \cdot \mathrm{dL}^{-1}$ & $3.05 \pm 0.57$ \\
\hline C-reactive protein $\mathrm{mg} \cdot \mathrm{L}^{-1}$ & $50.92 \pm 49.63$ \\
\hline
\end{tabular}

Data are presented as $\mathrm{n}$ or mean \pm SD. APACHE: Acute Physiology and Chronic Health Evaluation; $P \mathrm{aO}_{2}$ : arterial oxygen tension; $\mathrm{PaCO}_{2}$ : arterial carbon dioxide tension; $\mathrm{FlO}_{2}$ : inspiratory oxygen fraction. 


\begin{tabular}{|c|c|c|c|}
\hline & NIV & No NIV & p-value \\
\hline Subjects & 40 & 158 & \\
\hline Male/female & $21 / 19$ & $108 / 50$ & 0.158 \\
\hline Age years & $64.74 \pm 13.78$ & $60.99 \pm 15.52$ & 0.780 \\
\hline Medical/surgical cause of critical illness & $30 / 10$ & $87 / 71$ & 0.048 \\
\hline Charlson index & $1.97 \pm 1.34$ & $1.45 \pm 1.61$ & 0.153 \\
\hline APACHE II & $14.00 \pm 3.55$ & $11.81 \pm 5.51$ & 0.037 \\
\hline Intensive care stay days & $43.25 \pm 20.32$ & $40.40 \pm 29.75$ & 0.850 \\
\hline Mechanical ventilation in intensive care days & $34.81 \pm 18.45$ & $35.96 \pm 20.69$ & 0.606 \\
\hline Respiratory care unit stay days & $58.97 \pm 38.09$ & $51.73 \pm 31.20$ & 0.275 \\
\hline Weaning time at respiratory care unit days & $29.00 \pm 17.56$ & $23.77 \pm 16.42$ & 0.211 \\
\hline 1-year mortality \% & 12.1 & 12.8 & 0.876 \\
\hline $\begin{array}{l}\text { Pressure support on mechanical } \\
\text { ventilation } \mathrm{cmH}_{2} \mathrm{O}\end{array}$ & $20.34 \pm 1.03$ & $21 \pm 0.92$ & 0.876 \\
\hline PEEP $\mathrm{cmH}_{2} \mathrm{O}$ & $4.32 \pm 0.01$ & $4.93 \pm 0.02$ & 0.765 \\
\hline $\begin{array}{l}\text { Back-up respiratory rate on mechanical } \\
\text { ventilation breaths } \cdot \mathrm{min}^{-1}\end{array}$ & $13.21 \pm 0.93$ & $14.01 \pm 0.23$ & 0.854 \\
\hline pH & $7.38 \pm 0.06$ & $7.35 \pm 0.09$ & 0.055 \\
\hline $\mathrm{PaO}_{2} \mathrm{mmHg}$ & $94.87 \pm 27.76$ & $99.31 \pm 61.46$ & 0.628 \\
\hline $\mathrm{PaCO}_{2} \mathrm{mmHg}$ & $50.32 \pm 10.33$ & $43.95 \pm 8.56$ & 0.004 \\
\hline $\mathrm{FiO}_{2}$ & $0.38 \pm 0.7$ & $0.37 \pm 0.16$ & 0.437 \\
\hline Leukocytes per L & $9968.18 \pm 2685.28$ & $10042.29 \pm 3832.71$ & 0.975 \\
\hline Neutrophils \% & $72.05 \pm 12.53$ & $75.92 \pm 11.12$ & 0.233 \\
\hline Haemoglobin $\mathrm{g} \cdot \mathrm{dL}^{-1}$ & $9.70 \pm 1.62$ & $9.54 \pm 1.46$ & 0.777 \\
\hline Haematocrit \% & $29.09 \pm 5.24$ & $28.95 \pm 4.50$ & 0.963 \\
\hline Platelets per $\mathrm{L}$ & $284454.54 \pm 0.01$ & $307065.57 \pm 0.01$ & 0.461 \\
\hline Sodium mmol. $\mathrm{L}^{-1}$ & $138.86 \pm 5.87$ & $138.36 \pm 4.53$ & 0.763 \\
\hline Potassium mmol. $\mathrm{L}^{-1}$ & $4.10 \pm 0.54$ & $4.03 \pm 0.56$ & 0.476 \\
\hline Blood urea nitrogen $\mathrm{mg} \cdot \mathrm{dL}^{-1}$ & $55.86 \pm 49.58$ & $47.90 \pm 30.17$ & 0.512 \\
\hline Creatinine $\mathrm{mg} \cdot \mathrm{dL}^{-1}$ & $0.84 \pm 0.76$ & $0.70 \pm 0.45$ & 0.443 \\
\hline Serum albumin $\mathrm{g} \cdot \mathrm{dL}^{-1}$ & $3.10 \pm 0.65$ & $3.02 \pm 0.55$ & 0.550 \\
\hline C-reactive protein $\mathrm{mg} \cdot \mathrm{L}^{-1}$ & $38.06 \pm 39.70$ & $57.12 \pm 54.38$ & 0.132 \\
\hline
\end{tabular}

\section{Discussion}

The findings of the present study show that NIV is a useful tool during the weaning process in patients with chronic critical illness, regardless of their premorbid medical conditions. Moreover, chronically critically ill patients with hypercapnia despite MV at respiratory care unit admission could benefit from NIV with regard to achieving successful weaning.

Chronic critical illness represents a syndrome that is mediated by the host's systemic inflammatory response and is characterised by prolonged MV, profound muscle weakness, neuroendocrine changes, nutritional deficiencies, increased vulnerability to infection, brain dysfunction and skin breakdown [1]. The results of the present study are consistent with recent epidemiological studies [14, 15] showing a chronically critical ill population with a mean age of $\sim 62$ years with several comorbid conditions. The mean Charlson comorbidity index score of our patients $(1.73 \pm 1.74)$ is similar to that reported by previous authors [15]. Our patients presented prolonged ICU stays, with a mean duration of MV in the ICU of $36.74 \pm 23.93$ days. Patient's mortality in the present study during the respiratory care unit stay $(12.6 \%)$ is similar to previous studies $[8,10,16,17]$. We used SBT as the weaning method, which has recently been found to be the method which achieves weaning success in the shortest time in patients with prolonged MV. Our results show a weaning success rate of $87.5 \%$ with a median weaning time from respiratory care unit admission of 21 days. Across all the studies that report successful liberation from MV in chronic critical illness, the rate of weaning success is $57 \%$ (95\% CI 55-60) [18]. Similar results to ours regarding weaning success have been reported previously $[8,19,20]$. Reasons for this high rate could be due to: differences in definitions (chronic critical illness, prolonged MV, weaning success, etc.) or patient selection between the different previous studies; the use of an organised approach to weaning undertaken at the 


\section{TABLE 3 Predictors of need for noninvasive ventilation during weaning: univariate analysis}

\begin{tabular}{|c|c|c|}
\hline & OR $(95 \% \mathrm{CI})$ & p-value \\
\hline Male & $0.570(0.281-1.157)$ & 0.119 \\
\hline Age years & $1.018(0.992-1.044)$ & 0.173 \\
\hline Medical cause of critical illness & $2.803(1.278-6.147)$ & 0.010 \\
\hline Charlson index & $1.212(0.977-1.502)$ & 0.080 \\
\hline Tobacco & $3.536(1.469-8.512)$ & 0.005 \\
\hline COPD & $0.879(0.364-2.125)$ & 0.879 \\
\hline OSA & $0.239(0.066-0.874)$ & 0.030 \\
\hline CHF & $0.316(0.137-0.733)$ & 0.007 \\
\hline Ischaemic cardiopathy & $0.369(0.189-2.158)$ & 0.470 \\
\hline Chronic renal failure & $0.202(0.064-0.641)$ & 0.007 \\
\hline Neoplasm & $1.263(0.494-3.224)$ & 0.626 \\
\hline Hypertension & $0.861(0.428-1.732)$ & 0.674 \\
\hline Diabetes mellitus & $1.543(0.628-3.788)$ & 0.344 \\
\hline Atrial fibrillation & $3.750(0.801-17.555)$ & 0.093 \\
\hline Premorbid home CPAP & $0.245(0.058-1.027)$ & 0.054 \\
\hline Premorbid home NIV & $0.082(0.008-0.814)$ & 0.033 \\
\hline Apache II & $1.082(1.006-1.165)$ & 0.035 \\
\hline Critical care stay & $1.003(0.990-1.017)$ & 0.629 \\
\hline Mechanical ventilation duration at critical care & $0.997(0.972-1.023)$ & 0.187 \\
\hline pH & $30.29(0.114-8056.41)$ & 0.231 \\
\hline $\mathrm{PaO}_{2}$ & $0.998(0.988-1.008)$ & 0.735 \\
\hline $\mathrm{PaCO}_{2}$ & $1.078(1.015-1.146)$ & 0.015 \\
\hline $\mathrm{FiO}_{2}$ & $1.648(0.050-54.064)$ & 0.779 \\
\hline Leukocytes & $1.00(1.00-1.00)$ & 0.933 \\
\hline Haematocrit & $1.006(0.906-1.118)$ & 0.907 \\
\hline Platelets & $1.00(1.00-1.00)$ & 0.483 \\
\hline Sodium & $1.021(0.925-1.128)$ & 0.678 \\
\hline Potassium & $1.249(0.519-3.008)$ & 0.619 \\
\hline Blood urea nitrogen & $1.006(0.993-1.018)$ & 0.385 \\
\hline Creatinine & $1.547(0.673-3.556)$ & 0.305 \\
\hline Serum albumin & $1.306(0.539-3.165)$ & 0.555 \\
\hline C-reactive protein & $0.991(0.979-1.003)$ & 0.144 \\
\hline
\end{tabular}

specific and specialised units located in the acute hospital; and the use of multidisciplinary care and the utilisation of NIV in those patients with weaning failure. In fact, if those patients in whom NIV was used are excluded from the weaning success group, our weaning rate is $68 \%$, which is more in line with the rates reported in other studies [18].

Despite weaning protocols, multidisciplinary approaches and specialised care, some patients remain ventilator-dependent and weaning success cannot be achieved. In such cases, NIV has been reported to be useful during the weaning process in patients with chronic critical illness [19, 21, 22]. Although there is lack of evidence supporting the effectiveness of NIV with chronically critically ill patients, NIV in this population is normally used for those patients who require only nocturnal ventilatory support. In the present study, $21.4 \%$ of the successful cases of weaning were achieved using NIV. Previous studies have specifically analysed the role of NIV in patients with prolonged MV [8, 9, 19]. In the study by ScHonHofer et al. [9], 403 (28.81\%) patients received NIV during the weaning process due to significant hypercapnia after $24 \mathrm{~h}$ of spontaneous breathing; $31.5 \%$ of the discharged patients continued using NIV during the night at home. The NIV group was younger, used MV for a shorter period and had lower APACHE II scores at admission. In a study focusing only on COPD patients with prolonged MV, QuinNell et al. [8] applied criteria for NIV initiation very similar to ours. NIV was used during the weaning protocol with $59.70 \%$ of the patients included in the study [8]. Of those patients who used NIV 62\% were discharged to their homes with long-term NIV. In a study of 117 COPD patients with prolonged weaning, HeINEMANN et al. [19] recorded 82 successfully weaned patients, $39(47.6 \%)$ of whom required home NIV due to persistent chronic ventilatory failure. Home NIV was associated with a higher rate of survival after 1 year. In the present study, the NIV group had higher APACHE II scores and $\mathrm{PaCO}_{2}$ at respiratory care unit admission and the critical cause triggering 
chronically critical illness was a medical condition; moreover, patients with premorbid obstructive sleep apnoea, congestive heart failure and chronic renal failure were more likely to require NIV despite there being no differences in the Charlson comorbidity index, and this was also the case for those using continuous positive airway pressure or NIV previously at home. However, the only factor that we found that predicted the need for NIV during the weaning process was the presence of hypercapnia despite the use of MV at respiratory care unit admission. This finding suggests that, after the critical episode, these patients were probably in a worse thoracopulmonary condition, preventing them from achieving spontaneous breathing by themselves and therefore needing NIV in order for invasive MV to be removed. In this way, Sellares et al. [23] have found that those patients with prolonged weaning presented with greater $\mathrm{PaCO}_{2}$ under $\mathrm{MV}$, although other studies did not find differences [24, 25].

Reported 1-year mortality for prolonged MV ranges between 40\% and 75\% [18], which is higher than in patients requiring short-term MV [26]. In prolonged MV patients, successful weaning does not ensure long-term survival; chronically critically ill patients have underlying comorbid conditions, residual organ dysfunction and intercurrent complications that increase the risk of death [27]. In fact, for prolonged MV, advanced age, poor previous functional status and residual organ failures have been reported to be associated with greater mortality [28, 29]. In the present study, 1-year mortality was found to in the lower range of those reported previously [18]. This variability in survival reported by the different studies reflects differences in single centre patient selection, patient care practice and patient characteristics. Previous studies [8-10] have found home NIV after discharge to be a prognostic factor for long-term survival in chronically critically ill patients $[8,19]$. However, our results do not demonstrate any difference in the rate of mortality at 1 year in relation with NIV.

The main limitation of the study is its observational design. Perhaps, over a longer period, these patients could have achieved weaning success without NIV, and so a randomised controlled trial would demonstrate the real value of NIV during the weaning of such patients. Another limitation concerns the different treatment approaches, mainly with regard to the two techniques that were used to affect the transfer to NIV, a capped tracheostomy tube and a tracheal button. We did not find differences between the two approaches although the presence of an intratracheal cannula can lead to an increase in airway resistance and work of breathing [30].

In conclusion, for those chronically critically ill patients managed at an respiratory care unit who present with $\mathrm{PaCO}_{2}>45 \mathrm{mmHg}$ after $24 \mathrm{~h}$ of spontaneous breathing or for whom it proves impossible to increase the duration of SBT beyond $18 \mathrm{~h}$, the use of NIV can be a useful procedure with regard to achieving weaning success. The main predictor of the need for NIV during weaning in chronically critically ill patients is the presence of hypercapnia despite MV at respiratory care unit admission.

\section{Acknowledgements}

The members of the Spanish Respiratory Intermediate Care Units Group are as follows. Chairman: Fernando Masa (Hospital San Pedro Alcántara, Cáceres, Spain). Members: Eva Farrero and Enric Prats (Hospital Bellvitge, Barcelona); Josep Monserrat and Cristina Embid (Hospital Clinic, Barcelona); Antonio Antón and Patricia Peñacoba (Hospital de la Santa Creu I Sant Pau, Barcelona); Javier Gómez de Terreros, M. Jesús Martín-Vicente and Isabel Utrabo (Hospital San Pedro Alcántara, Cáceres); Lidia Mendez (Hospital Lucus Agusti, Lugo); Javier Sayas and Pedro Benavides (Hospital 12 de Octubre, Madrid); Ana Santiago and M. Antonia Mendieta (Hospital La Paz, Madrid); Enrique Zamora and Gonzalo Segrelles (Hospital Universitario de La Princesa, Madrid); Juan A. Piña and José J. Cebrian (Hospital Costa del Sol, Malaga); Ramón Fernandez-Alvarez and Francisco Rodriguez-Jerez (Hospital Universitario Central de Asturias; Oviedo), M. Belen Núñez, Alicia Binimelis and Ernest Sala (Hospital Son Espases, Palma de Mallorca); Raquel Catala (Hospital Sant Joan, Reus); Luis Jara-Palomares, Raquel Sánchez-Oro-Gómez and Emilia Barrot (Hospital Virgen del Rocio, Sevilla); Angel Ortega-Gonzalez and José Serrano-Rebollo (Hospital Nuestra Señora del Prado, Talavera de la Reina); Jesus Sancho and Emilio Servera (Hospital Clínico Universitario, Valencia); Joaquin Durán and Pedro J Rivas (Hospital Txagorritxu, Vitoria); Carlos J Egea (Hospital Vithas San José, Vitoria); Myriam Aburto and Cristobal Esteban (Hospital Galdakao, Vizcaya, all Spain).

\section{References}

Carson SS. Definitions and epidemiology of the chronically critically ill. Respir Care 2012; 57: 848-856. Carson S, Bach P. The epidemiology and costs of chronic critical illness. Crit Care Clin 2002; 18: 461-476. Boles JM, Bion J, Connors A, et al. Weaning from mechanical ventilation. Eur Respir J 2007; 29: 1033-1056. Epstein SK. Weaning the "unweanable": liberating patients from prolonged mechanical ventilation. Crit Care Med 2007; 35: 2640-2641.

5 Jubran A, Grant GJB, Duffner LA, et al. Effect of pressure support $v s$ unassisted breathing through a tracheostomy collar on weaning duration in patients requiring prolonged mechanical ventilation. JAMA 2013; 309: 671-677.

6 Burns KE, Meade MO, Premji A, et al. Noninvasive positive pressure ventilation as a weaning strategy for intubated adults with respiratory failure: a Cochrane systematic review. CMAJ 2014; 186: E112-E122.

7 Glossop AJ, Shephard N, Bryden DC, et al. Noninvasive ventilation for weaning, avoiding reintubation after extubation and in the postoperative period: a meta-analysis. Br J Anaesth 2012; 109: 305-314.

8 Quinnell TG, Pilsworth S, Shneerson JM, et al. Prolonged invasive ventilation following acute ventilator failure in COPD. Weaning results, survival and the role of noninvasive ventilation. Chest 2006; 129: 133-139. 
9 Schönhofer B, Euteneuer S, Nava S, et al. Survival of mechanically ventilated patients admitted to a specialized weaning centre. Intensive Care Med 2002; 28: 908-916.

10 Rose L, Fraser IA. Patient characteristics and outcomes of a provincial prolonged ventilation weaning centre: a retrospective cohort study. Can Respir J 2012; 19: 216-220.

11 MacIntyre NR, Epatein SK, Carson S, et al. Management of patients requiring prolonged mechanical ventilation: report of a NAMDRC consensus conference. Chest 2005; 128: 3937-3954.

12 Charlson ME, Pompei P, Ales KL, et al. A new method of classifying prognostic comorbidity in longitudinal studies: development and validation. J Chronic Dis 1987; 40: 373-383.

13 Knaus WA, Draper EA, Wagner DP, et al. APACHE II: a severity of disease classification system. Crit Care Med 1985; 13: 818-829.

14 Kahn JM, Le T, Angus DC, et al. The epidemiology of chronic critical illness in the United States. Crit Care Med 2015; 43: 282-287.

15 Carson SS, Cox CE, Holmes CM, et al. The changing epidemiology of mechanical ventilation: a population based study. J Intensive Care Med 2006; 21: 173-182.

16 Hannan LM, Tan S, Hopkinson K, et al. Inpatient and long-term outcomes of individuals admitted for weaning from mechanical ventilation at a specialized weaning unit. Respirology 2013; 18: 154-160.

17 Gracey DR, Hardy DC, Naessens JM, et al. The Mayo Ventilator-Dependent Rehabilitation Unit: a 5-year experience. Mayo Clin Proc 1997; 72: 13-19.

18 Damuth E, Mitchell JA, Bartock JL, et al. Long-term survival of critically ill patients treated with prolonged mechanical ventilation: a systematic review and meta-analysis. Lancet Respir Med 2015; 3: 544-553.

19 Heinemann F, Budweiser S, Jörres RA, et al. The role of home noninvasive ventilation in patients with chronic obstructive pulmonary disease requiring prolonged weaning. Respirology 2011; 16: 1273-1280.

20 Gracey DR, Naessens JM, Krishan I, et al. Hospital and posthospital survival in patients mechanically ventilated for more than 29 days. Chest 1992; 10: 211-214.

21 Pilcher DV, Bailley MJ, Treacher DF, et al. Outcomes, cost and long term survival of patients referred to a regional weaning centre. Thorax 2005; 60: 187-192.

22 Scheinhorn DJ, Hassenpflug MS, Votto JJ, et al. Post-ICU mechanical ventilation at 23 long-term care hospitals a multicenter outcomes study. Chest 2007; 131: 85-93.

23 Sellares J, Ferrer M, Cano E, et al. Predictors of prolonged weaning and survival during ventilator weaning in a respiratory ICU. Intensive Care Med 2011; 37: 775-784.

24 Jubran A, Tobin MJ. Pathophysiologic basis of acute respiratory distress in patients who fail a trial of weaning from mechanical ventilation. Am J Respir Crit Care Med 1997; 155: 906-915.

25 Vitacca M, Ambrosino N, Clini E, et al. Physiological response to pressure support ventilation delivered before and after extubation in patients not capable of totally spontaneous autonomus breathing. Am J Respir Crit Care Med 2001; 164: 638-641.

26 Cox CE, Carson SS, Lindquist JH, et al. Differences in one-year health outcomes and resource utilization by definition of prolonged mechanical ventilation: a prospective cohort study. Crit Care 2007; 11: R9.

27 Nelson JE, Cox CE, Hope AA, et al. Chronic critical illness. Am J Respir Crit Care Med 2010; 182: 446-454

28 Carson SS, Bach PB, Brzozowski L, et al. Outcomes after long-term acute care. An analysis of 133 mechanically ventilated patients. Am J Respir Crit Care Med 1999; 159: 1568-1573.

29 Dematte D'Amico JE, Donnelly HK, Mutlu GM, et al. Risk assessment for inpatient survival in the long-term acute care setting after prolonged critical illness. Chest 2003; 124: 1039-1045.

30 Beard B, Monaco MJ, Wilmoth D, et al. Tracheostomy discontinuation: impact of tube selection on resistance during tube occlusion. Respir Care 1993; 38: 267-270. 